\section{Plasma Physics Division}

The Board of the Plasma Physics Division meet on 24 June 1990, the Sunday before the Annual Divisional Conference in Amsterdam. The most important business related to future conferences. It was decided to combine our 1992 conference with the International Conference on Plasma Physics (ICPP) which will take place in Innsbruck on 29 June -5 July 1992 . It was also decided to organize in the week after ICPP a satellite meeting on radiofrequency heating and current drive in Brussels. The 1993 Division conference will be held in Portugal.

At the end of this year we shall have to elect the Division Board for 1991-1993. According to the Division's Statutes, no more than six members of the present Board may be re-elected. I therefore invite members of the Division to discuss with their colleagues possible candidates and to provide me with their names. The candidates must be members of the Plasma Physics Division. Each nomination should be accompanied by a statement of consent by the candidate, a one line description of his or her activity, and the names of five mem bers of the Plasma Physics Division supporting the candidature.

The members of the present Board who are eligible for re-election are:

G.M. McCracken, Culham (UK)

J.T. Mendonça, Lisbon (P)

D.D. Ryutov, Novosibirsk (USSR)

H. Schlüter, Bochum (FRG)

S. Segre (Vice-Chairman), Rome (I)

F. Sluijter (Vice-Chairman), Eindhoven (NL)

J. Tachon, Cadarache (F)

R.R. Weynants, Brussels (B)

To ensure a smooth transition into the new term, the Board has elected F. Sluijter as its Chairman from 1 October 1990.

Please send nominations before $30 \mathrm{Sep}$ tember 1990 to:

Miss Edith Grüter, CRPP/EPFL,

Avenue des Bains 21, CH-1007 Lausanne.

\section{K. Appert}

Chairman of the Board
Teraflops

Lattice QCD has held out the hope that low energy properties of hadronic physics could be calculated from first principles. Calculations are now made using meshes of $32^{4}$. Further significant improvements in results will most likely come from an orders of magnitude increase in computer performance (both speed and memory).

In computer jargon, this means working in the teraflop range. Those interested in exploring the possibilities of a coordinated teraflop initiative in Europe have been asked to participate at a meeting on 27 - 28 November 1990 at CERN. Following presentations of the various national developments, it is aimed to discuss ideas for future projects, joint efforts and dedicated facilities with the overall objective to perhaps coordinate the different approaches.

Further information is available from $\mathbf{H}$. Satz at CERN (E-mail: tera @ cernvm; tel: ++412276724 66; fax: ++4122782 39 14) a member of the meeting's steering and local organizing committees which were set up earlier in the year.

\section{Letter to the Editor The Way Forward}

\section{Dear Sir,}

I was very interested to read in your May issue the reports of the Council meeting in Uppsala on 29-30 March. As an IOM representative, I can certainly confirm that there was a sense of determination that the Society should meet the challenge of playing a significant role in the scientific life of a rapidly changing Europe, and that it should seek all possible means to overcome its financial difficulties and increase membership. I myself spoke briefly on behalf of the IOM's, and although a couple of my remarks have been reported I would like IOM's to know a little more of what I actually said.

It is fair to say that the financial problems of the Society dominated the discussions at Uppsala. IOM's certainly know how serious the situation is since they were the subject of a special appeal during the year. I do not want to go over all the ground again here, but to concentrate on a specific issue, the artificiality of our budget. This is highlighted by two of the ways which were considered by Council for alleviating the situation, namely, reducing the Geneva staff and being less ambitious with Europhysics News. I gave it as my opinion that neither of these made any sense whatever. If the EPS is to remain viable, it must have a minimum staff and it must provide an organ of communication which people will want to read. Before I had much to do with the Geneva staff, I was as prepared as anyone to sup pose that there was room for economy in this area. I am now quite convinced that there is not. The staff consists of a smal number of dedicated people whose function would be seriously jeopardized by any cutback. And to change policy on Europhysics News now, after the splendid work which has been done over the last year or so, would be to say the least very unfortunate. So how on earth does it come about that we are contemplating such steps? Because they are almost the only parts of our budget over which we have any real control.

We are thus in the position that we have not enough income to maintain the minimum expenditure required to provide the basic service which makes it worthwhile to run the Society, and run the risk of cutting the service below that limit because it is the only route open to us. Well, to Council's credit, that route was not followed; and efforts are being redoubled to find new sources of money, increase membership, and so on. We all hope for miracles, and they are more likely to happen the more thought and effort we all put in. But how did we get into this position in the first place, given what I believe to be the efficiency of the whole operation? My earlier remarks lead to the conclusion that it is a matter of insufficient income rather than waste of money or excessive provision for the membership. Where do we traditionally get money from? Some from IOM subscriptions, of course, but most comes from the national societies. Now it seems to have occurred by some mischance that these contributions are just sufficient to keep the EPS staggering along in a perpetual state of crisis. When I put this to Council, it was underlined to me how generous the national societies have been, and are now, to the EPS, and indeed the President makes the same point in the May issue of this journal. I am very happy to accept this; I am not on any committee of Council, so I know little of the discussions which take place between the representatives of the societies and the EPS. However, it seems to me that if ever there was a time for a major increase in the scale of this generosity, it is now. The equation simply does not balance, and virtually nothing can be done about the outgoings, short of closing down. There can surely be no question about the gravity of the problem, nor of the commitment of Council to doing its utmost to get on top of it. It may well be that the national societies are already doing all they reasonably can; but if so, we had all better start praying for miracles and looking for fairy godmothers. Thus, while it is absolutely essential that the EPS should do everything it possibly can to raise income from other sources, I suggest that it is time to re-examine the whole structure and scale of the scheme of contributions made by national societies.

It is often pointed out that the financial situation would improve if we could attract more IOM's. At the European Conference on Atomic and Molecular Physics in Bordeaux in March 1989, a suggestion (since known as the "Bordeaux initiative") was put forward which attracted some support. This was that all members of national societies should automatically be full IOM's. They would have to pay a higher fee than the present national society subscription, but the difference would be far less than the amount one now pays to be an IOM because of the enormous increase one would have in the membership. Well, why not? Maybe members of the national societies would not actually want to do it; but in the present European climate, with enough publicity and some vigorous backing from the national societies themselves, who knows?

It would, Sir, be very interesting to have this possibility discussed in your columns. May I invite your readers to write in and express their views? The IOM delegates need feedback to represent the IOM's adequately, and these issues do seem to be of some importance.

D.N. Stacey

Clarendon Laboratory, Oxford 